\title{
Correlation between the expression of inflammatory cytokines IL-6, TNF- $\alpha$ and hs-CRP and unfavorable fetal outcomes in patients with pregnancy-induced hypertension
}

\author{
DEHUA KONG ${ }^{1 *}$, HUI WANG ${ }^{2 *}$, YAN LIU $^{3}$, HONGJUN LI ${ }^{4}$, HONGYAN WANG ${ }^{5}$ and PENG ZHU ${ }^{1}$ \\ ${ }^{1}$ Department of Obstetrics, Jining First People's Hospital, Jining, Shandong 272000; \\ ${ }^{2}$ Reproductive Center, Yantaishan Hospital, Yantai, Shandong 264000; \\ ${ }^{3}$ Department of Surgery People's Hospital of Zhangqiu; \\ ${ }^{4}$ EEG Room, Jinan Zhangqiu District Hospital of TCM; \\ ${ }^{5}$ Department of Obstetrics, People's Hospital of Zhangqiu, \\ Jinan, Shandong 250000, P.R. China
}

Received January 8, 2018; Accepted June 21, 2018

DOI: $10.3892 /$ etm.2018.6393

\begin{abstract}
The expression of inflammatory factors, tumor necrosis factor- $\alpha$ (TNF- $\alpha$ ), interleukin-6 (IL-6) and highsensitivity C-reactive protein (hs-CRP), in patients with pregnancy-induced hypertension $(\mathrm{PIH})$ was investigated, to analyze correlation of expression levels of these factors in patients with unfavorable fetal outcome. A total of 100 patients diagnosed with PIH treated in Jining First People's Hospital (Jining, China) from January 2012 to October 2017 were selected as the experimental group, while 100 normal pregnant women during the same period were selected as the control group. Results showed that the levels of IL- 6 , TNF- $\alpha$ and hs-CRP in patients with PIH were significantly higher than those in normal pregnant women $(\mathrm{p}<0.01)$. There were significant differences in levels of IL-6, TNF- $\alpha$ and hs-CRP among patients with hypertension in different degrees. The expression levels of IL-6, TNF- $\alpha$ and hs-CRP in PIH patients with favorable pregnancy outcome were lower than those in patients with unfavorable pregnancy outcome $(\mathrm{p}<0.05)$. Moreover, the expression levels of IL-6, TNF- $\alpha$ and hs-CRP had a linearly positive correlation with systolic blood pressure in PIH patients. Age, height and weight had no significant correlation with unfavorable pregnancy outcome of PIH patients $(\mathrm{p}>0.05)$. Finally, inflammatory factors (TNF- $\alpha$, IL-6 and hs-CRP) and blood pressure were obviously and positively correlated with unfavorable pregnancy
\end{abstract}

Correspondence to: Dr Peng Zhu, Department of Obstetrics, Jining First People's Hospital, 6 Jiankang Road, Jining, Shandong 272000, P.R. China

E-mail:n5i830@163.com

${ }^{*}$ Contributed equally

Key words: pregnancy-induced hypertension, IL-6, TNF- $\alpha$, hs-CRP, unfavorable fetal outcome outcome of PIH patients $(\mathrm{p}<0.05)$. In conclusion, the expression of inflammatory factors (TNF- $\alpha$, IL-6 and hs-CRP) in PIH patients are positively correlated with the systolic blood pressure and unfavorable fetal outcome of patients, which can be used as indexes of prognosis evaluation of PIH patients.

\section{Introduction}

Hypertensive disease developed in pregnancy is called pregnancy-induced hypertension (PIH), including chronic hypertension, pre-eclampsia, eclampsia, hypertension in pregnancy and pre-eclampsia complicated by chronic hypertension, which is a disease occurring in the specific period of pregnancy (1). Hypertensive disease during pregnancy brings great harm to the health of parturients and infants, which is an important cause of neonatal and maternal deaths (2). It is common worldwide that hypertensive disease occurs in the pregnancy period with an incidence rate of $10 \%$. The incidence rate in other countries is slightly higher than that in China, which may be related to the dietary differences between them (3). There are four causes of PIH. First, it is believed that the occurrence of hypertension in pregnancy is associated with oxidative stress, which can lead to the production of inflammatory factors so as to cause hypertension. Second, it is considered that PIH is related to heredity, and people with genetic predisposition are susceptible to the disease. Third, it is held that this disease is associated with adverse immune response. Immunologic abnormality can lead to hypertension in pregnancy, and it is considered that the occurrence of hypertension in pregnancy is related to placental ischemia. It has been confirmed by many scholars that the immunological theory is involved in the development of PIH (4-7). Endothelial injury and cytokines are involved in the process of immune activation. In recent years, increased number of studies on cytokines have been carried out (8-10). Interleukin-6 (IL-6) is a $26 \mathrm{kDa}$ cytokine with complex physiological functions. It is produced by activated macrophages, monocytes and $\mathrm{T}$ lymphocytes $(\mathrm{T}$ cells) (11). The role of IL-6 is to induce the differentiation 
and growth of cells and factors in different types, levels and organs (12-15). Some scholars have found that the IL-6 level in patients with PIH is higher than that in patients with normal pregnancy. Maternal and infant prognoses in patients with high level of IL-6 are worse than those in the pregnant women with normal IL-6 level, indicating that IL-6 exerts effects on the prognosis of patients with PIH (16). Activated natural killer (NK) cells, $\mathrm{T}$ cells and macrophages can secrete a large number of tumor necrosis factors (TNFs) (17). TNF- $\alpha$ has multiple functions, as it not only has an anti-infection effect, but also can promote proliferation and differentiation of cells. Moreover, it has side effects damaging endothelial cells or causing vascular dysfunction. Since PIH is closely associated with vascular endothelium injury, it is believed that TNF- $\alpha$ is related to PIH. C-reactive protein (CRP) is a protein produced under stress of the body, which can help the body combat against external invasion and clean up the 'garbage' generated inside the body so as to provide protective effects (18). Therefore, CRP plays an important role in the organism when it receives external invasion, namely the effect of anti-inflammation. It has been recognized by scholars for many years that CRP is a non-specific inflammatory marker. However, recent studies have found a certain correlation between CRP and atherosclerosis. In addition, studies have shown that CRP is one of the strongest predictors and risk factors of cardiovascular disease. Thus it is inferred that CRP is associated with PIH. In this study, the expression of TNF- $\alpha$, IL- 6 and high-sensitivity C-reactive protein (hs-CRP) in patients with $\mathrm{PIH}$ were examined to investigate the relationship between the poor pregnancy outcomes, such as stillbirth, and PIH.

\section{Patients and methods}

General data. The expression levels of TNF- $\alpha$, IL- 6 and hs-CRP in 100 patients with PIH treated in Jining First People's Hospital (Jining, China) from January 2012 to October 2017 as well as the correlation between the expression levels of these factors in patients with PIH and fetal adverse outcomes were studied and analyzed. One hundred normal pregnant women at the same period were selected as the control group. The average age of these 200 pregnant women was $27.1 \pm 3.0$ years and the average gestational age was $39.3 \pm 1.9$ weeks. This study was approved by the Ethics Committee of Jining First People's Hospital. Signed informed consents were obtained from all participants before the study.

Standard collection. Elbow venous blood $(5 \mathrm{ml})$ of patients were taken and left to stand. Then, supernatants were removed. IL- 6 and TNF- $\alpha$ in serum were detected through enzymelinked immunosorbent assay (ELISA) and hs-CRP level was determined through immunological transmission turbidimetry.

Judgement of adverse pregnancy outcomes. The adverse pregnancy outcomes include preterm birth, stillbirth, fetal death, neonatal asphyxia and death.

Statistical analysis. Whether there was a correlation between the two variables was analyzed. The odds ratio (OR) and the $95 \%$ confidence interval were used to select variables related to each other in the univariate logistic regression analysis. The
Table I. Comparison of the inflammatory factors IL-6, TNF- $\alpha$ and hs-CRP between normal pregnancy and PIH.

\begin{tabular}{lcc}
\hline Factors & $\begin{array}{c}\text { Normal pregnancy } \\
(\mathrm{n}=100)\end{array}$ & $\begin{array}{c}\text { PIH } \\
(\mathrm{n}=100)\end{array}$ \\
\hline $\begin{array}{l}\text { Inflammatory factor } \\
\text { IL-6 }(\mathrm{pg} / \mathrm{ml})\end{array}$ & $1.79 \pm 0.37$ & $3.42 \pm 0.45^{\mathrm{a}}$ \\
$\begin{array}{l}\text { Inflammatory factor } \\
\text { TNF- } \alpha(\mu \mathrm{g} / \mathrm{ml})\end{array}$ & $1.13 \pm 0.41$ & $4.98 \pm 1.25^{\mathrm{a}}$ \\
$\begin{array}{l}\text { Inflammatory factor } \\
\text { hs-CRP }(\mathrm{mg} / \mathrm{ml})\end{array}$ & $1.33 \pm 0.89$ & $5.12 \pm 1.88^{\mathrm{a}}$ \\
\hline
\end{tabular}

${ }^{a} \mathrm{p}<0.01$. IL-6, interleukin-6; TNF- $\alpha$, tumor necrosis factor- $\alpha$; hs-CRP, high-sensitivity C-reactive protein.

Table II. The relationships between the grade of hypertension in patients with PIH and the inflammatory factors IL-6, TNF- $\alpha$ and hs-CRP.

\begin{tabular}{lccc}
\hline Factors & $\begin{array}{c}\text { Grade I } \\
\text { hypertension }\end{array}$ & $\begin{array}{c}\text { Grade II } \\
\text { hypertension }\end{array}$ & $\begin{array}{c}\text { Grade III } \\
\text { hypertension }\end{array}$ \\
\hline $\begin{array}{l}\text { Inflammatory factor } \\
\text { IL-6 }(\mathrm{pg} / \mathrm{ml})\end{array}$ & $1.98 \pm 0.39$ & $2.30 \pm 0.41^{\mathrm{b}}$ & $4.73 \pm 0.50^{\mathrm{a}}$ \\
$\begin{array}{l}\text { Inflammatory factor } \\
\text { TNF- } \alpha(\mu \mathrm{g} / \mathrm{ml})\end{array}$ & $1.77 \pm 0.75$ & $2.96 \pm 1.34^{\mathrm{b}}$ & $5.16 \pm 1.87^{\mathrm{a}}$ \\
$\begin{array}{l}\text { Inflammatory factor } \\
\text { hs-CRP }(\mathrm{mg} / \mathrm{ml})\end{array}$ & $1.92 \pm 0.77$ & $3.18 \pm 1.32^{\mathrm{b}}$ & $6.76 \pm 1.97^{\mathrm{a}}$ \\
\end{tabular}

${ }^{\mathrm{a}} \mathrm{p}<0.01$ (compared with grades I and II); ${ }^{\mathrm{b}} \mathrm{p}<0.05$ (compared with grade I). IL-6, interleukin-6; TNF- $\alpha$, tumor necrosis factor- $\alpha$; hs-CRP, high-sensitivity $\mathrm{C}$-reactive protein.

data analysis was conducted through Statistical Product and Service Solutions (SPSS) 19.0 software (IBM SPSS, Armonk, NY, USA). The data calculated in this study were expressed by the mean \pm standard deviation. $\mathrm{P}<0.05$ were considered to indicate statistically significant differences.

\section{Results}

Comparisons of the inflammatory factors IL-6, TNF- $\alpha$ and hs-CRP between normal pregnancy and PIH. One hundred normal pregnant women and 100 patients with PIH were compared. The levels of IL-6, TNF- $\alpha$ and hs-CRP in patients with $\mathrm{PIH}$ were much higher than those in normal pregnant women. The differences were statistically significant $(\mathrm{p}<0.01)$ (Table I).

Relationships between the grade of hypertension in patients with PIH and the inflammatory factors IL- $6, T N F-\alpha$ and $h s-C R P$. The inflammatory factors IL-6, TNF- $\alpha$ and hs-CRP at grades I-III hypertension were compared in each two groups and the differences were significant (Table II).

Correlation between the pregnancy outcome of patients with $P I H$ and inflammatory factors IL-6, TNF- $\alpha$ and $h s-C R P$. 
Table III. Correlation between pregnancy outcome of patients with PIH and inflammatory factors IL-6, TNF- $\alpha$ and hs-CRP.

\begin{tabular}{lcc}
\hline & \multicolumn{2}{c}{ PIH (n=100) } \\
\cline { 2 - 3 } Factors & $\begin{array}{c}\text { Good pregnancy } \\
\text { outcomes }(54)\end{array}$ & $\begin{array}{c}\text { Adverse pregnancy } \\
\text { outcomes (46) }\end{array}$ \\
\hline $\begin{array}{l}\text { Inflammatory factor } \\
\text { IL-6 (pg/ml) }\end{array}$ & $2.13 \pm 0.56$ & $3.72 \pm 0.87^{\mathrm{b}}$ \\
$\begin{array}{l}\text { Inflammatory factor } \\
\text { TNF- } \alpha(\mu \mathrm{g} / \mathrm{ml})\end{array}$ & $2.15 \pm 0.77$ & $4.99 \pm 1.56^{\mathrm{a}}$ \\
$\begin{array}{l}\text { Inflammatory factor } \\
\text { hs-CRP }(\mathrm{mg} / \mathrm{ml})\end{array}$ & $3.11 \pm 0.68$ & $5.42 \pm 1.12^{\mathrm{a}}$ \\
\hline
\end{tabular}

${ }^{\mathrm{a}} \mathrm{p}<0.01,{ }^{\mathrm{b}} \mathrm{p}<0.05$. IL-6, interleukin-6; TNF- $\alpha$, tumor necrosis factor- $\alpha$ hs-CRP, high-sensitivity C-reactive protein.

Table IV. Logistic regression analysis for risk factors of the adverse pregnancy outcomes in patients with PIH.

\begin{tabular}{lccc}
\hline Risk factors & P-value & OR value & $95 \%$ CI \\
\hline Age (years) & 0.134 & 1.074 & $0.887,1.256$ \\
Height & 0.647 & 0.712 & $0.109,6.226$ \\
Weight & 0.616 & 5.954 & $1.217,23.156$ \\
TNF- $\alpha$ & 0.019 & 1.301 & $0.923,1.509$ \\
CRP & 0.035 & 1.521 & $0.689,2.562$ \\
IL-6 & 0.041 & 2.452 & $1.734,3.058$ \\
Blood pressure & 0.005 & 4.347 & $1.718,15.152$ \\
\hline
\end{tabular}

PIH, pregnancy-induced hypertension.

According to the aforementioned diagnostic criteria, the adverse pregnancy outcomes include preterm birth, stillbirth, intrauterine fetal death, neonatal asphyxia and death. Based on this standard, the levels of inflammatory factors TNF- $\alpha$ and hs-CRP in patients with good pregnancy outcomes were significantly lower than those in patients with adverse pregnancy outcomes $(\mathrm{p}<0.01)$. The level of inflammatory factor IL-6 in patients with good pregnancy outcomes was also lower than that in patients with adverse pregnancy outcomes $(\mathrm{p}<0.05)$ (Table III).

Correlation between the expression of IL- $6, T N F-\alpha$ and $h s-C R P$ and the levels of systolic blood pressure in patients. The expression of IL-6, TNF- $\alpha$ and hs-CRP in patients was linearly positively correlated with systolic blood pressure of patients with PIH ( $r=0.646, r=0.711, r=0.692)$ (Figs. 1-3).

Logistic regression analysis for risk factors of the adverse pregnancy outcomes in patients with PIH. Analysis of univariate logistic correlation found that there were no correlations of age, height and weight with the adverse pregnancy outcomes of patients with PIH $(p>0.05)$. Inflammatory factors TNF- $\alpha$, CRP, IL-6 and blood pressure levels were correlated to the

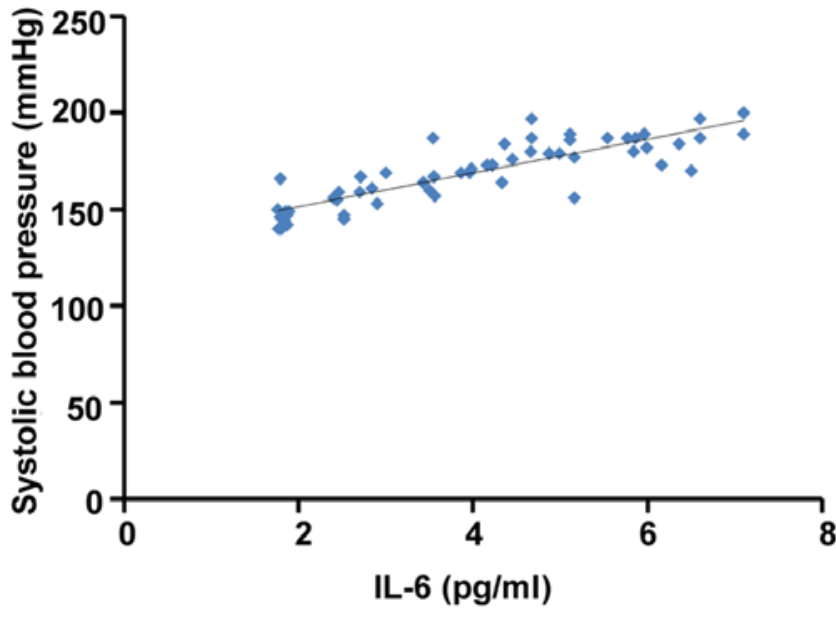

Figure 1. Analysis of correlation between hypertension level and the level of inflammatory factor IL-6, r=0.646. IL-6, interleukin-6.

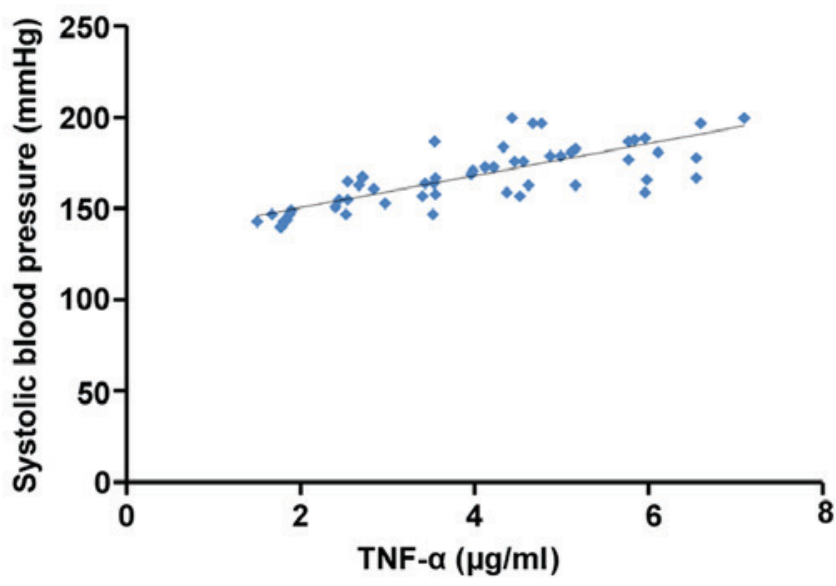

Figure 2. Analysis of correlation between hypertension level and the level of inflammatory factor TNF- $\alpha, r=0.711$. TNF- $\alpha$, tumor necrosis factor- $\alpha$.

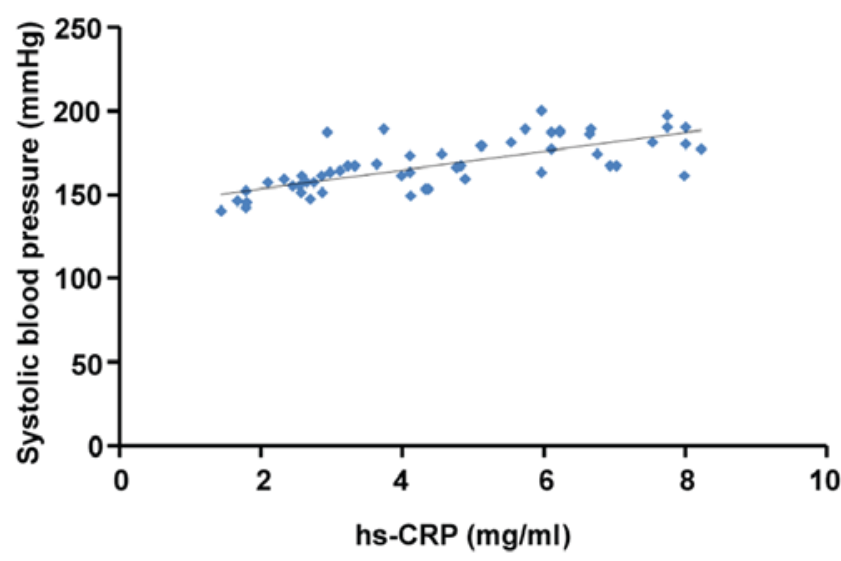

Figure 3. Analysis of correlation between hypertension level and the level of inflammatory factor hs-CRP, $r=0.692$. hs-CRP, high-sensitivity C-reactive protein.

adverse pregnancy outcomes of patients with PIIH $(\mathrm{p}<0.05)$ and they were positively correlated with the adverse pregnancy outcomes (OR value $>1$ ) (Table IV). 


\section{Discussion}

$\mathrm{PIH}$ is an important complication during the perinatal period, which is a very important cause of maternal and fetal death or neonatal death (19). For normal pregnancy, the placental trophoblasts will break through the spiral artery of the placental bed and then conduct the retrograde infiltration along the vessel wall to destroy elastic fibers of vessel wall until they reach the myometrium of spiral artery. This change reduces the resistance of maternal blood flowing to fetal blood which makes it easier for the fetus to obtain blood and the nutrients dissolved in blood from the mother. However, when PIH occurs, the physiological changes of spiral artery cannot reach the myometrium, which will result in the fibrinoid necrosis of the muscular layer and acute atherosclerosis. This result will reduce the blood flow to the placenta, thereby affecting the amount of blood received by the fetus, and then further affecting the growth of the fetus. Neonatal asphyxia and premature delivery are the frequent consequences of these causes, and in severe cases stillbirth will be caused (20).

In recent years, it has been generally believed that PIH is associated with immune imbalance, and cytokines, especially inflammatory factors, play important roles in immune regulation. Therefore, in this study, the relationship between three common cytokines and the adverse pregnancy outcomes of patients with PIH was investigated in order to find new methods for the diagnosis and treatment of PIH in patients. In this study, the levels of IL-6, TNF- $\alpha$ and hs-CRP in patients with PIH were significantly higher than those in the normal pregnant women $(\mathrm{p}<0.01)$;. The inflammatory factors IL-6, TNF- $\alpha$ and hs-CRP at grades I-III hypertension were compared in each two groups and the differences were significant. The expression of IL-6 in PIH patients with good pregnancy outcomes was significantly lower than that in patients with poor pregnancy outcomes $(\mathrm{p}<0.05)$. Therefore, the expression of these inflammatory factors in patients with PIH were related to the pregnancy outcomes, and they were linearly positively correlated with the systolic blood pressure level in patients with PIH. Age, height and weight were not related to the adverse pregnancy outcomes of patients with PIH ( $>>0.05)$, while the inflammatory factors TNF- $\alpha, \mathrm{CRP}$, the level of blood pressure and IL-6 were correlated with the adverse pregnancy outcomes of patients with $\mathrm{PIH}(\mathrm{p}<0.05)$. In addition, they were positively associated with adverse pregnancy outcomes (OR value $>1$ ). Therefore, it is concluded that the expression of IL-6, TNF- $\alpha$ and hs-CRP in patients with PIH can be used to predict the occurrence of the adverse pregnancy outcomes in this period.

In conclusion, IL- 6 , TNF- $\alpha$ and hs-CRP in patients with $\mathrm{PIH}$ are positively correlated with the systolic blood pressure level and the adverse outcomes of neonatal asphyxia and stillbirth, can be used as indicators of prognosis evaluation for patients with PIH. In subsequent studies, it will be further analyzed whether the reduction of the inflammatory factors IL-6, TNF- $\alpha$ and hs-CRP by a series of drug interventions can improve the pregnancy outcomes in patients with $\mathrm{PIH}$, hence finding the new treatment options for PIH.

\section{Acknowledgements}

Not applicable.

\section{Funding}

No funding was received.

\section{Availability of data and materials}

All data generated or analyzed during this study are included in this published article.

\section{Authors' contributions}

DK and HW designed the study. YL and HL collected the patient data. HW and PZ analyzed the patient data. All authors have read and approved the final manuscript.

\section{Ethics approval and consent to participate}

This study was approved by the Ethics Committee of Jining First People's Hospital (Jining, China). Signed informed consents were obtained from all participants before the study.

\section{Patient consent for publication}

Not applicable.

\section{Competing interests}

The authors declare that they have no competing interests.

\section{References}

1. Ames M, Rueda J and Caughey AB: Ambulatory management of chronic hypertension in pregnancy. Clin Obstet Gynecol 55: 744-755, 2012

2. Mustafa R, Ahmed S, Gupta A and Venuto RC: A comprehensive review of hypertension in pregnancy. J Pregnancy 2012: 105918, 2012.

3. Wilson KL, Casey BM, McIntire DD, Halvorson LM and Cunningham FG: Subclinical thyroid disease and the incidence of hypertension in pregnancy. Obstet Gynecol 119: 315-320, 2012.

4. Vest AR and Cho LS: Hypertension in pregnancy. Curr Atheroscler Rep 16: 395, 2014.

5. Mangos GJ, Spaan JJ, Pirabhahar S and Brown MA: Markers of cardiovascular disease risk after hypertension in pregnancy. $\mathrm{J}$ Hypertens 30: 351-358, 2012.

6. Rosengarten D, Blieden LC and Kramer MR: Pregnancy outcomes in pulmonary arterial hypertension in the modern management era. Eur Respir J 40: 1304-1305, 2012.

7. Lazzarin N, Desideri G, Ferri C, Valensise H, Gagliardi G, Tiralongo GM and Manfellotto D: Hypertension in pregnancy and endothelial activation: An emerging risk factor for cardiovascular disease. Pregnancy Hypertens 2: 393-397, 2012.

8. Shi Y, Pan H, Zhang HZ, Zhao XY, Jin J and Wang HY: Lipoxin A4 mitigates experimental autoimmune myocarditis by regulating inflammatory response, $\mathrm{NF}-\kappa \mathrm{B}$ and $\mathrm{PI} 3 \mathrm{~K} / \mathrm{Akt}$ signaling pathway in mice. Eur Rev Med Pharmacol Sci 21: 1850-1859, 2017.

9. Al Khaja KA, Sequeira RP, Alkhaja AK and Damanhori AH Drug treatment of hypertension in pregnancy: A critical review of adult guideline recommendations. J Hypertens 32: 454-463, 2014.

10. Perni U, Sison C, Sharma V, Helseth G, Hawfield A, Suthanthiran M and August P: Angiogenic factors in superimposed preeclampsia: A longitudinal study of women with chronic hypertension during pregnancy. Hypertension 59: 740-746, 2012

11. Graham BB, Chabon J, Kumar R, Kolosionek E, Gebreab L, Debella E, Edwards M, Diener K, Shade T, Bifeng G, et al: Protective role of IL-6 in vascular remodeling in Schistosoma pulmonary hypertension. Am J Respir Cell Mol Biol 49: 951-959, 2013. 
12. Teixeira AA, Quinto BM, Dalboni MA, Rodrigues CJ and Batista MC: Association of IL-6 polymorphism -174G/C and metabolic syndrome in hypertensive patients. BioMed Res Int 2015: 927589, 2015.

13. Karaman E, Urhan Kucuk M, Bayramoglu A, Uzun Göçmen S Ercan S, Guler HI, Kucukkaya Y and Erden S: Investigation of relationship between IL- 6 gene variants and hypertension in Turkish population. Cytotechnology 67: 947-954, 2015.

14. Lukic L, Lalic NM, Rajkovic N, Jotic A, Lalic K, Milicic T, Seferovic JP, Macesic M and Gajovic JS: Hypertension in obese type 2 diabetes patients is associated with increases in insulin resistance and IL-6 cytokine levels: Potential targets for an efficient preventive intervention. Int J Environ Res Public Health 11: 3586-3598, 2014.

15. Dimas G, Iliadis F, Tegos T, Spiroglou S, Kanellos I, Karamouzis I, Savopoulos C, Hatzitolios A and Grekas D: 4B.08: Serum levels of TIMP-1 and IL- 6 are associated with hypertension and atherosclerosis in patients with early stages of chronic kidney disease and type 2 diabetic nephropathy. J Hypertens 33 (Suppl 1): e55, 2015.

16. Repke JT: Hypertension in pregnancy. I. Md Med J 36: 473-475, 1987.
17. Murdaca G, Spanò F, Contatore M, Guastalla A, Penza E, Magnani $O$ and Puppo F: Infection risk associated with anti-TNF- $\alpha$ agents: A review. Expert Opin Drug Saf 14: 571-582, 2015.

18. Ridker PM: From C-reactive protein to interleukin-6 to interleukin-1: Moving upstream to identify novel targets for atheroprotection. Circ Res 118: 145-156, 2016.

19. Firoz T, Magee LA, MacDonell K, Payne BA, Gordon R, Vidler M and von Dadelszen P; Community Level Interventions for Pre-eclampsia (CLIP) Working Group: Oral antihypertensive therapy for severe hypertension in pregnancy and postpartum: A systematic review. BJOG 121: 1210-1220, 2014.

20. Easterling TR: Pharmacological management of hypertension in pregnancy. Semin Perinatol 38: 487-495, 2014.

(c) (i) $\Theta$ This work is licensed under a Creative Commons c) At No ND Atribution-NonCommercial-NoDerivatives 4.0 International (CC BY-NC-ND 4.0) License. 